\title{
DNA Methylation and Flavonoids in Genitourinary Cancers
}

\author{
Neelam Mukherjee • Addanki P. Kumar • Rita Ghosh
}

Published online: 20 January 2015

(C) Springer International Publishing AG 2015

\begin{abstract}
Malignancies of the genitourinary system have some of the highest cancer incidence and mortality rates. For example, prostate cancer is the second most common cancer in men and ovarian cancer mortality and incidence are near equal. In addition to genetic changes, modulation of the epigenome is critical to cancer development and progression. In this regard, epigenetic changes in DNA methylation state and DNA hypermethylation in particular have garnered a great deal of attention. While hypomethylation occurs mostly in repeated sequence such as tandem and interspersed repeats and segment duplications, hypermethylation is associated with $\mathrm{CpG}$ islands. Hypomethylation leads to activation of cancer-causing genes with global DNA hypomethylation
\end{abstract}

This article is part of the Topical Collection on Epigenetics and Phytochemicals

N. Mukherjee · A. P. Kumar · R. Ghosh $(\bowtie)$

Department of Urology, School of Medicine, University of Texas

Health Science Center at San Antonio, 8403 Floyd Curl Drive, San

Antonio, TX 78229, USA

e-mail: ghoshr@uthscsa.edu

N. Mukherjee

e-mail: mukherjeeN@livemail.uthscsa.edu

A. P. Kumar

e-mail: kumara3@uthscsa.edu

A. P. Kumar • R. Ghosh

Department of Pharmacology, School of Medicine, University of

Texas Health Science Center at San Antonio, San

Antonio, TX 78229, USA

A. P. Kumar • R. Ghosh

Department of Molecular Medicine, School of Medicine, University of Texas Health Science Center at San Antonio, San

Antonio, TX 78229, USA

A. P. Kumar

South Texas Veterans Health Care System, San Antonio, TX 78229, USA being commonly associated with metastatic disease. Hypermethylation-mediated silencing of tumor-suppressive genes is commonly associated with cancer development. Bioactive phytochemicals such as flavonoids present in fruits, vegetables, beverages, etc. have the ability to modulate DNA methylation status and are therefore very valuable agents for cancer prevention. In this review, we discuss several commonly methylated genes and flavonoids used to modulate DNA methylation in the prevention of genitourinary cancers.

Keywords Genitourinary cancers $\cdot$ Prostate $\cdot$ Urinary bladder · Kidney · Ovaries · Testicles · Cervix · Flavonoids . EGCG $\cdot$ Curcumin $\cdot$ Genistein $\cdot$ Epigenetics $\cdot$ DNA methylation

\section{Introduction}

Epigenetic modifications of DNA or associated proteins cause changes in gene expression without altering DNA sequence. This includes various pathways and mechanisms that maintain alternate states of chromatin structure by affecting protein composition and transcriptional activity through DNA methylation, histone modifications, nucleosome positioning, and non-coding RNAs [1]. Collectively, these processes are critical players that regulate accessibility of the transcription machinery to gene promoters [2]. Epigenetic changes that modify the contact between transcription machinery and gene promoters can lead to aberrant activation or inhibition of numerous signaling cascades resulting in different diseases including cancer [3]. Therefore, understanding epigenetic alterations involved in cancer development, progression, therapeutic response, and resistance hold great significance. Phytochemicals are plant-derived substances that can affect disease development and have 
been used for the prevention of chronic and degenerative diseases [4]. Flavonoids represent a class of low molecular weight polyphenolic phytochemicals found universally in plants [5]. Based on their chemical structure, they are categorized as flavonols, flavones, flavonones, isoflavones, catechins, anthocyanidins, and chalcones (see Fig. 1). They are characterized by a flavan nucleus and C6-C8-C6 carbon skeleton [5]. The antioxidant, anti-inflammatory, anti-thrombogenic, anti-angiogenic, and anti-cancer activities and their ubiquitous presence in fruits, vegetables, beverages, etc. underscore the importance of flavonoids in the human diet and diseases such as cancer [6]. Cancers of the genitourinary organ system include prostate, testicular, ovarian, cervical, urinary bladder, and kidney. Genitourinary cancers contribute to more than a fourth of the total cancer incidence in the USA and approximately $15 \%$ of cancer-related deaths. An estimated 480,000 people are expected to be diagnosed with these collective cancers, and more than 89,000 deaths are expected to occur in 2014 [7]. Prostate cancer is the second most commonly diagnosed cancer in men and is generally associated with aging men. Testicular germ cell tumors on the other hand are a common solid malignancy of young male adults that are either seminomas or nonseminomas and occur with almost equal frequency. Ovarian cancer is the most deadly form of gynecological cancer in women. Urinary bladder cancer has the infamous distinction of being within the top 10 most common cancers and the most common urinary system cancer that affects both men and women. Kidney cancer is the second most common urinary system cancer affecting both men and women. In this chapter, we discuss DNA methylation changes in different genitourinary cancers (summarized in Table 1), their ability to modulate expression of genes involved in cancer development and progression, and the role of flavonoids in regulating epigenetic modifications in these malignancies.

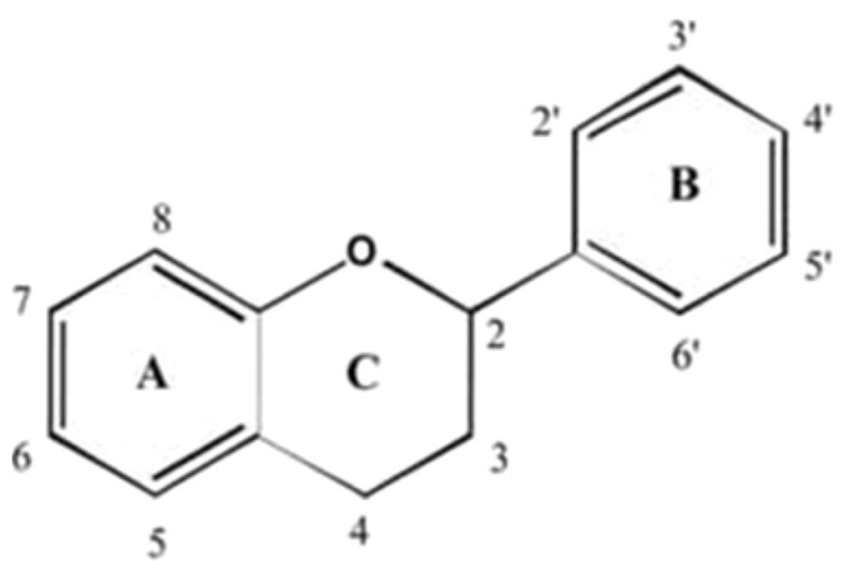

Fig. 1 Chemical structure of the flavan nucleus (adapted from www. mdpi.com)

\section{DNA Hypermethylation}

Archetypal $\mathrm{CpG}$ islands are devoid of methylation to allow transcription of required genes in the presence of essential cofactors and appropriate chromatin structure. DNA methylation at palindromic $\mathrm{CpG}$ sites by DNA methyltransferases (DNMTs) generates a pattern of methylated $\mathrm{CpG}$ dinucleotides at the $5^{\prime}$ end of the promoter of human genes. Methylation is a mechanism to control embryonic development, silence the X chromosome, prevent unwanted transcription, etc. DNA methylation can also occur in the "shore regions" of $\mathrm{CpG}$ islands, which have a comparatively lower CpG density $[8,9]$. DNA promoter hypermethylation-mediated transcriptional repression of genes prevents the binding of transcriptional activators and helps in the recruitment of methylcytosine-binding proteins (MBPs). These proteins help load DNMTs and histone deacetylases (HDACs) participating

Table 1 List of epigenetically silenced genes in GU malignancies with the target organs

\begin{tabular}{|c|c|c|}
\hline Name of genes & Type of cancer & Reference \\
\hline AR & Prostate and cervical & {$[19,35]$} \\
\hline $\begin{array}{l}\text { ER- } \alpha-A, \text { ER- } \alpha-B \text {, and } \\
\text { ER- } \alpha-C\end{array}$ & Prostate & {$[35]$} \\
\hline $\mathrm{PR}$ & Prostate and cervical & {$[19,35]$} \\
\hline Cyclin D2 & Prostate & {$[36]$} \\
\hline GSTP1 & Prostate & {$[42]$} \\
\hline $\begin{array}{l}\text { GSTM1, GPX3, and } \\
\text { MGMT }\end{array}$ & Prostate & [43-46] \\
\hline $\begin{array}{l}\text { APC, CAV1, cadherin 1, } \\
\text { CDH1, LAMA3, } \gamma 2 \\
\text { laminin, and TIMP3 }\end{array}$ & Prostate & {$[38,44,45,51]$} \\
\hline $\begin{array}{l}\text { DKK3, EDNRB, RUNX3, } \\
\text { and SFRP1 }\end{array}$ & Prostate & {$[38,43,44,46]$} \\
\hline DAPK & Prostate and cervical & {$[38-41]$} \\
\hline RARbeta2 & Cervical & {$[32]$} \\
\hline PTEN & Cervical & [19] \\
\hline RASSF1A & Cervical and renal & {$[20,21],[29]$} \\
\hline POU2F3 & Cervical & {$[22]$} \\
\hline E-cadherin & Cervical & {$[54]$} \\
\hline MGMT & Cervical and testicular & {$[20,47]$} \\
\hline Testisin & Testicular & {$[23 \bullet, 24]$} \\
\hline $\mathrm{p} 16^{\mathrm{INK} 4 \mathrm{a}}$ & Testicular and bladder & {$[23 \bullet, 24,25]$} \\
\hline HOXA9 and HOXB5 & Testicular & {$[57]$} \\
\hline $\begin{array}{l}\text { PIWIL1, PIWIL2, PIWIL4, } \\
\text { and TDRD1 }\end{array}$ & Testicular & {$[23 \bullet]$} \\
\hline p14 & Bladder & {$[26]$} \\
\hline $\begin{array}{l}\text { LAMA3, LAMB3, and } \\
\text { LAMC2 }\end{array}$ & Bladder & [49] \\
\hline VHL & Renal & {$[27,28]$} \\
\hline TU3A & Renal & {$[31]$} \\
\hline BRCA1 & Ovarian & {$[48]$} \\
\hline OPCML, ICAM-1, and CDH1 & Ovarian & {$[55,56]$} \\
\hline
\end{tabular}


in chromatin remodeling and transcriptional silencing [10, 11]. DNMT1 shows a preference for hemimethylated DNA and is considered to be a maintenance enzyme that keeps the methylation pattern intact after DNA replication $[12,13]$. DNMT3a and DNMT3b on the other hand do not distinguish between methylated substrates and are involved in de novo DNA methylation [13]. Loss of genome-wide DNA methylation and lethality of DNMT-knockout mice demonstrates the importance of these enzymes in mammalian development [14, 15]. DNA methylation is a critical process during germ cell development that relies heavily on DNMTs. Among them, the de novo DNMTs mainly exert their function during prenatal germ cell development while the maintenance DNMTs become critical in proliferating spermatogonia shortly after birth in the male [16]. Changes in DNA methylation profile and heritable decrease in DNA-5-MeC due to reduced DNA methylation fidelity maintenance was initially considered to be solely a hypomethylation process that resulted in overexpression of oncogenes [17]. However, the theory of demethylation of oncogenes leading to their activation has been replaced by the growing popularity of hypermethylation of tumor suppressor genes. These $\mathrm{CpG}$ islands become hypermethylated in malignant cells, thus inactivating certain tumor suppressor genes through a progressive process of numerous "waves" of dysregulated methylation unlike a gene mutation. There are two hypotheses by which hypermethylation takes place. The first is that methylation spreads from normal methylation centers to $\mathrm{CpG}$ islands devoid of methylation, and the second involves "seeding" of methylation that is already present and certain single-CpG dinucleotides become methylated inducing more cooperative methylation in the surrounding to finally lead to hypermethylation [18]. As discussed below, DNA methylation plays an important role in genitourinary cancers through the modulation of numerous genes that play critical roles in cancer cell biology [1]. Genes involved in the regulation of cellular processes such as hormone response, cell cycle progression, DNA damage and repair, signal transduction, and tumor invasion and architecture have deregulated hypermethylation providing the needed advantage to the sustenance of cancer cells.

\section{Tumor Suppressors}

The tumor suppressor phosphatase and tensin homolog (PTEN) is commonly silenced by promoter methylation in many of the genitourinary cancers. PTEN hypermethylation is an early event seen in patients with recurrent or fatal cervical cancer [19]. Several other potential tumor suppressors are atypically methylated in cervical cancer. Loss of Ras association domain family 1 isoform A (RASSF1A) leads to tumor progression, suggesting a tumor-suppressive role for this protein. In cervical cancer cells, hypermethylation of RASSF $1 A$ is a mechanism through which cervical cancer cells extinguish death receptor-mediated cell death $[20,21]$. Aberrant DNA methylation of the $P O U 2 F 3$ promoter, which is a transcription factor with putative tumor-suppressive function involved in cell type-specific differentiation, is common in cervical cancer [22]. Testisin, a putative tumor suppressor and testicular protease involved in sperm cell maturation, and the CDK inhibitor $\mathrm{p} 16^{\mathrm{INK} 4 \mathrm{a}}$ are hypermethylated in testicular cancer [23•, 24]. Methylation of the $\mathrm{p} 16^{\mathrm{INK} 4 \mathrm{a}}$ promoter and subsequent inactivation are involved in the initiation of bladder cancer [25]. Hypermethylation of the other gene product of $C D K N 2 A, \mathrm{p} 14$, in normal bladder samples after resection has been found to be a predictor of bladder cancer recurrence [26]. The most important genetic event in clear cell renal cell carcinoma (ccRCC) is the hypermethylation-mediated inactivation of the von Hippel-Lindau (VHL) tumor suppressor gene, which stabilizes hypoxia-inducible transcription factors HIF-1 and HIF-2 and the induction of a multitude of hypoxiainducible genes [27, 28]. RASSF1 is frequently methylated in sporadic renal cell carcinoma (RCC) (either biallelically or as a second hit following 3p deletion) [29]. RASSF1A methylation was detected in normal kidney tissues adjacent to the tumor but not in distant normal tissues, indicating that the TSG methylation is part of a "field effect" and an early event in cancer development causing epigenetic alterations in a large number of cells which is then accompanied by additional genetic and epigenetic changes [30]. Another tumor suppressor gene, TU3A (located at $3 \mathrm{p} 21.1$ ), is also found to be methylated in $42 \%$ of ccRCC and $25 \%$ of papillary renal cell carcinoma (pRCC) [31]. The FHIT gene that encodes a diadenosine triphosphate hydrolase is an important player in purine metabolism, and its promoter methylation has been seen in both ccRCC and pRCC [32]. Methylation of retinoic acid receptor beta (RAR beta), which regulates cell proliferation and differentiation, is also reported in less than $20 \%$ of RCC cases [32-34].

\section{Steroid Receptors}

Steroid receptors are critically involved in the regulation proliferation, differentiation, and development of prostate cells with the androgen receptor (AR) being a key player in prostate cancer. Interestingly late-stage prostate cancer tissues have methylated AR promoter, implicating methylation of the AR promoter as a late event in prostate cancer [35]. Estrogens, which are important in female sexual development, also affect benign prostatic hyperplasia and the development of prostate cancer with estrogen receptor (ER) expression being inversely correlated with histologic grade or pathologic stage of prostate cancer. The expression of ER- $\alpha$ isoforms was found to be dependent on the methylation status of their respective promoters with ER- $\alpha-C$ being unmethylated whereas ER- $\alpha-A$ and ER- $\alpha$-B being methylated in prostate cancer tissue samples [35]. Methylation of progesterone receptor (PR) is found 
in some prostate cancer cell lines and is believed to also be a late-stage event in prostate cancer [35]. Estrogen and progesterone receptor genes are also methylated in cervical cancer [19]. Retinoic acid receptor beta2 (RARbeta2) is methylated in invasive cervical cancer, and methylation levels were found to correlate with the pathological state of prostate cancer [32].

\section{Cell Cycle Regulation and Apoptosis}

D-type cyclins play a very important part in cell cycle regulation, and high cyclin D2 methylation levels have been associated with invasive prostatic carcinoma and clinically aggressive prostate cancer [36]. The human papillomavirus (HPV), a cervical cancer causative agent, can exist either in the integrated or episomal state in the cancer cells. The integrated form of HPV has been reported to be associated with methylation of the cell cycle regulatory protein cyclin A1 (CCNA1), which is inversely correlated with p53 mutation status in head and neck cancers [37]. Transcriptional silencing of apoptosis-related genes such as death-associated protein kinase (DAPK) due to aberrant promoter methylation leads to the impairment of the apoptotic machinery and disrupts cell growth and death homeostasis in prostate and cervical cancer cells [38-41].

\section{DNA Repair}

The glutathione $S$-transferases (GSTs) consist of a family of enzymes that convert electrophilic and hydrophobic compounds into more soluble and easily excreted forms by catalyzing their conjugation to glutathione. They participate in the detoxification of several potentially carcinogenic compounds, thereby contributing to cancer prevention. Glutathione $S$-transferase P1 (GSTP1) was one of the earliest genes identified to be hypermethylated in prostate cancer [42]. Subsequently, others such as glutathione $S$-transferase M1 (GSTM1), glutathione peroxidase 3 (GPX3), and $O$-6-methylguanine DNA methyltransferases ( $M G M T$ ) have been identified as having hypermethylated promoters in prostate cancer [43-46]. $M G M T$ encodes an enzyme involved in DNA repair and removes alkylated guanine in DNA through stoichiometric transfer of the alkyl group at the $O-6$ position to a cysteine residue. Methylation of the $M G M T$ promoter leads to its inactivation and the development of nonseminomatous testicular cancer and is also seen in cervical cancer [20,47]. Given the importance of oxidative stress in cancer, loss of function of gene products involved in neutralizing oxidative DNA damage is of great significance. Promoter hypermethylation of BRCA1 observed in ovarian cancer may be an alternative mechanism in silencing the tumor-suppressive function of this gene in ovarian cancer [48].
Migration, Invasion, and Metastasis

Laminins are components of the extracellular matrix (ECM) that maintain the architecture of the basal lamina surrounding the epithelial cells and modulate cell migration and invasion, whereas the E-cadherin-catenin complex plays a key part in epithelial cell-cell adhesion and tissue architecture. Methylation of $L A M A 3$ and $L A M B 3$ has been found to be associated with poor grade and stage in bladder cancer, while the methylation of $L A M C 2$ has been linked to a drop in survival time in patients [49]. Aberrant methylation of the LN5 and E-cadherin has been found to correlate with clinicopathological features and invasion in prostate cancer [50, 51]. Other genes implicated in tumor invasion such as familial adenomatous polyposis $(A P C)$, caveolin $1(C A V 1)$, cadherin 1CD44, cluster differentiation antigen $(C D H 1), \alpha-3$ laminin (LAMA3), $\gamma 2$ laminin (LAMC2), and TIMP3 have also been found to undergo hypermethylation in prostate cancer $[38,44,45,51]$. In bladder cancer, downregulation of the $C D H 1$ gene through promoter hypermethylation is frequently correlated with staging and grading of bladder cancer, but the relation with methylation patterns is somewhat inconsistent with other studies showing high to low level of methylation at the promoter of $C D H 1$ in bladder cancer $[45,52,53]$. Promoter methylation of E-cadherin is also seen in cervical cancer [54]. Other cell adhesion genes including $O P C M L, I C A M-1$, and $C D H 1$ are hypermethylated in ovarian cancer $[55,56]$.

\section{Miscellaneous}

Genes involved in normal development such as the homeobox genes (HOXA9 and HOXB5) are variably methylated in testicular cancer [57]. Global methylation at long interspersed nuclear element-1 (LINE-1) is inherited in familial testicular cancer kindred [58]. Interestingly, hypermethylation-mediated silencing of the small regulatory PIWI-interacting RNAs (piRNAs) including PIWIL1, PIWIL2, PIWIL4, and TDRD1, which regulate male germ line development, has been observed in primary seminoma and non-seminoma testicular cancer [23]. Several genes involved in signal transduction including Dickkopf ( $D K K 3)$, endothelin receptor type $\mathrm{B}$ (EDNRB), RASSF1A, runt-related transcription factor 3 (RUNX3), and secreted frizzled-related protein 1 (SFRP1) have been found to be hypermethylated in prostate cancer $[38,43,44,46]$.

\section{Hypomethylation}

Loss of DNA methylation was the first reported epigenetic change in human cancer [59]. Approximately half of the genome comprises of highly repeated DNA sequences, which 
contribute to the global DNA hypomethylation commonly observed in cancers [60-62]. The most commonly studied DNA hypomethylated repeats in cancer include tandem centromeric satellite a, juxta-centromeric satellite 2 , interspersed Alu, and LINE-1 repeats $[61,62,63 \bullet \bullet, 64,65]$. The association between loss of methylation in mice lacking DNMT or fed methyl-deficient diet and cancer development provides evidence for the involvement of DNA hypomethylation in cancer development $[66,67]$. In general, unlike hypermethylation, hypomethylation of transcriptional regulatory sites in cancer appears to occur infrequently [68]. Hypomethylation of gene promoters in cancer is associated with decreased overall genomic methylation or satellite DNA that correlates with increased transcription [69-72]. Evidence for the contribution of gene region hypomethylation to oncogenesis suggests a greater involvement in activating genes involved with tumor invasion and metastasis as well as drug resistance $[73,74]$.

\section{DNA Hypomethylation in Genitourinary Cancers}

DNA hypomethylation appears to be a late event in prostate cancer contrary to other cancers. Although some LINE-1 promoter hypomethylation is seen in primary prostate cancer, the extent of hypomethylation is much greater when there is lymph node involvement [75]. Hypomethylation of wingless-related MMTV integration site 5A (WNT5A), S100 calcium-binding protein $\mathrm{P}($ S10OP), and cysteine-rich protein 1 (CRIPI) has been observed in prostate cancer [76]. Hypomethylation and overexpression of the protease urokinase are associated with prostate cancer progression [77]. Testicular germ cell seminomas display a large amount of genomic hypomethylation, although this may be linked to the cell type from which this tumor originates [78]. Hypomethylation has been found to cause re-expression of previously hypermethylated genes, such as the $H R A S, B C L 2, A B C B 1$, $S 100 A 4, S N C G$, and $C C N D 2$ [39], and numerous cancer-/testis-associated genes [40] in testicular cancer. Global DNA hypomethylation has been observed in cervical cancer, and increased DNA hypomethylation is involved in progression and appears to correlate with grade [79]. Hypomethylation of satellite DNA has been observed in ovarian cancer and found to increase with stage and grade of ovarian cancer. Further, hypomethylation of satellite 2 DNA correlates with poor prognosis [80]. Genomic DNA hypomethylation is considered to be a biomarker for bladder cancer with increased LINE1 hypomethylation and greater number of hypomethylated loci in cells derived from blood and urine of bladder cancer patients [81]. Heparanase, an enzyme that acts both on the cell surface and within the extracellular matrix to degrade polymeric heparan sulfate molecules into shorterchain-length oligosaccharides, is also regulated by hypomethylation in bladder cancer [82].

\section{Flavonoids as Modulators of DNA Methylation}

Fruits, vegetables, and other plant products used in beverages are a rich source of polyphenols with flavonoids accounting for a large proportion of the polyphenolic compounds. Almost all categories of flavonoids have cancer prevention properties due either to their antioxidant or antiinflammatory properties. However, a comprehensive analysis of the effect of this class of polyphenolic compounds on DNA methylation-mediated effects in cancer still remains to be carried out. Table 2 shows the flavonoids that have been tested in GU malignancies.

Flavonols include quercetin, myricetin, catechins, etc. Quercetin is present in red onions, buckwheat, red grapes, apple skin, green tea, etc. It also forms the structural backbone of the flavonones hesperitin. Despite its ability to demethylate the $\mathrm{p} 16^{\mathrm{INK} 4 \mathrm{a}}$ gene promoter in colon cancer cells, its ability to modulate DNA methylation in genitourinary cancers remains to be vigorously tested. Quercetin was shown to decrease bladder cancer cell growth and to induce apoptosis by decreasing the DNA methylation of the estrogen receptor (ER- $\beta$ ), $\mathrm{p} 16^{\mathrm{INK} 4 \mathrm{a}}$, and RASSF1A [83]. Myricetin, which is found in many grapes, berries, fruits, vegetables, and herbs, can also decrease DNA methylation by inhibiting SssI DNMT [84].

The green tea polyphenol (-)-epigallocatechin-3-O-gallate (EGCG) is the most studied catechin. It inhibits tumorigenesis partially by affecting DNA methylation through inhibition of DNMTs [84]. EGCG can re-express many transcriptionally silenced genes through inhibition of DNMT1 enzymatic activity in prostate cancer cell lines [85-89]. EGCG was shown to decrease growth and induce apoptosis in renal cell carcinoma by re-expressing tissue factor pathway inhibitor-2 (TFPI2), a member of the Kunitz-type serine proteinase inhibitor family, and decreasing its promoter hypermethylation [90]. EGCG also decreases the promoter methylation of other genes such as hTERT and CDX2, thereby helping in tumor suppression $[91,92]$.

Isoflavones present in legumes, pomegranate seeds, etc. are another important group of dietary flavonoids, which includes the soybean isoflavone genistein. Genistein has been most widely studied for its effect on DNA methylation in cancer including genitourinary cancers. Genistein has also been shown to exert its anticancer effect through modulation of

Table 2 List of commonly tested flavonoids in GU malignancies

\begin{tabular}{lll}
\hline Flavonoid & Targeted cancer & Reference \\
\hline Quercetin & Bladder & {$[83]$} \\
$\begin{array}{c}\text { (-)-Epigallocatechin-3- } \\
\text { O-gallate (EGCG) }\end{array}$ & Bladder and renal & {$[85-90]$} \\
$\begin{array}{l}\text { Genistein } \\
\text { Curcumin }\end{array}$ & Prostate and cervical & {$[93,95,96]$} \\
\hline
\end{tabular}


DNA methylation $[93,94]$. Genistein can change DNA methylation at gene promoters in the prostate of $\mathrm{C} 57 \mathrm{BL} / 6 \mathrm{~J}$ mice [95]. Genistein was also found to decrease DNMT activity resulting in transcriptional activation of genes such as p16 ${ }^{\mathrm{INK} 4 \mathrm{a}}$, RAR beta, MGMT, PTEN, and CYLD in prostate cancer and RAR beta 2 in cervical cancer [93, 96]. Genistein-mediated modulation of methylation of protumorigenic miRNA-1260b and its targets SFRP1 and Smad4 inhibits prostate cancer cell proliferation, invasion, and TCF reporter activity [97•]. Genistein upregulates the GTP-binding RAS-like gene $(A R H I)$, which is an imprinted tumor suppressor gene that is downregulated in prostate cancer [98].

Other common dietary phenolic compounds found in many fruits and vegetables including hesperetin, naringin, apigenin, and luteolin can also modulate DNA methylation. Apigenin, a flavone found in parsley, artichoke, basil, celery, and other plants, has been shown to inhibit the hypermethylation of various tumor suppressor genes. It has also been shown to reduce MssI enzyme-mediated hypermethylation in prostate epithelial cells [99]. Although these compounds are not as efficient as EGCG in directly inhibiting DNMT activity, they can indirectly regulate DNMT activity by regulating the ratio of $S$-adenosyl methionine (SAM) and $S$-adenosyl homocysteine (SAH) during their metabolic methylation by catechol- $O$ methyltransferase (COMT) [84, 100]. Curcumin was found to bring about global hypomethylation in the MV4-11 leukemia cell line by inhibiting DNMT [101]. It was also found to negatively regulate DNMT1 in ovarian cancer and melanoma $[102,103]$. Curcumin was also observed to decrease $\mathrm{CpG}$ promoter methylation of Neurog1, a highly hypermethylated marker in prostate cancer [104], and also the hypermethylation at the promoter region of the tumor suppressor retinoic acid receptor 2 gene in cervical cancer [105]. It was also found to be involved in the re-expression of $\mathrm{Nrf} 2$, a critical regulator of the antioxidant response, by reducing promoter hypermethylation in transgenic adenocarcinoma of the mouse prostate (TRAMP) prostate cancer cells [106]. Curcumin also reduces hypermethylation of the Fanconi anemia (FANCF) promoter, thereby regulating growth and proliferation in cervical cancer [107].

\section{Future Directions}

Clearly, dietary components including flavonoids affect DNA methylation patterns. Most reports in the literature have used in vitro model systems to test the demethylation effects of bioactive dietary compounds to restore functions associated with tumor suppression. It remains unclear how demethylation of methylated cytosines in the gene promoter regions would affect hypomethylation given the suggestion that there is crosstalk between demethylation and de novo methylation pathways during tumorigenesis that can make one pathway dependent on the other. Future work is needed to systematically analyze the influence of these bioactive components on the distribution of DNA methylation and demethylation patterns in cancer and normal tissues in order to predict the usefulness of these agents as clinical epigenetic modulators. Further, more attention should be exercised with regard to dietary consumption of bioactive foods in clinical trials when DNMT inhibitors are being tested. Future studies should include a more thorough investigation of specific flavonoids to determine their global epigenetic effects and how they influence outcomes in normal and cancer states. Differential effects on each flavonoid on specific genes and their functional outcomes need further elucidation. Obtaining a comprehensive understanding of the capabilities of flavonoids can result in their development as novel, natural epigenetic modulators for cancer prevention.

Acknowledgments This work was supported in part by CA149516 (RG) and 1R01AT7448 (APK).

\section{Compliance with Ethics Guidelines}

Conflict of Interest Neelam Mukherjee, Addanki P Kumar, and Rita Ghosh declare that they have no conflict of interest.

Human and Animal Rights and Informed Consent This article does not contain any studies with human or animal subjects performed by any of the authors.

\section{References}

Papers of particular interest, published recently, have been highlighted as:

- Of importance

•. Of major importance

1. Sharma S, Kelly T, Jones P. Epigenetics in cancer. Carcinogenesis. 2010;31:27-36.

2. Egger G, Liang G, Aparicio A, Jones P. Epigenetics in human disease and prospects for epigenetic therapy. Nature. 2004;429: 457-63.

3. Jones $\mathrm{P}$, Baylin $\mathrm{S}$. The fundamental role of epigenetic events in cancer. Nat Rev Genet. 2002;3:415-28.

4. Calhoun L, Kwon Y. Structure, function and regulation of the DNA-binding protein Dps and its role in acid and oxidative stress resistance in Escherichia coli: a review. J Appl Microbiol. 2011;110:375-86.

5. Heim K, Tagliaferro A, Bobilya D. Flavonoid antioxidants: chemistry, metabolism and structure-activity relationships. J Nutr Biochem. 2002;13:572-84.

6. Kühnau J. The flavonoids. A class of semi-essential food components: their role in human nutrition. World Rev Nutr Diet. 1976;24:117-91.

7. Siegel R, Ma J, Zou Z, Jemal A. Cancer statistics, 2014. CA: Cancer J Clin. 2014;64:9-29.

8. Irizarry R, Ladd-Acosta C, Wen B, Wu Z, Montano C, Onyango P, et al. The human colon cancer methylome shows similar 
hypo- and hypermethylation at conserved tissue-specific $\mathrm{CpG}$ island shores. Nat Genet. 2009;41:178-86.

9. Doi A, Park I-H, Wen B, Murakami P, Aryee M, Irizarry R, et al. Differential methylation of tissue- and cancer-specific $\mathrm{CpG}$ island shores distinguishes human induced pluripotent stem cells, embryonic stem cells and fibroblasts. Nat Genet. 2009;41:1350-3.

10. Scarano M, Strazzullo M, Matarazzo M, D’Esposito M. DNA methylation 40 years later: its role in human health and disease. J Cell Physiol. 2005;204:21-35.

11. Vaissière T, Sawan C, Herceg Z. Epigenetic interplay between histone modifications and DNA methylation in gene silencing. Mutat Res. 2008;659:40-8.

12. Jeltsch A. On the enzymatic properties of Dnmt1: specificity, processivity, mechanism of linear diffusion and allosteric regulation of the enzyme. Epigenetics: Off J DNA Methylation Soc. 2006;1:63-6.

13. Jurkowska R, Jurkowski $\mathrm{T}$, Jeltsch A. Structure and function of mammalian DNA methyltransferases. Chembiochem: Eur J Chem Biol. 2011;12:206-22.

14. Li E, Bestor T, Jaenisch R. Targeted mutation of the DNA methyltransferase gene results in embryonic lethality. Cell. 1992;69: 915-26.

15. Okano M, Bell D, Haber D, Li E. DNA methyltransferases Dnmt3a and Dnmt3b are essential for de novo methylation and mammalian development. Cell. 1999;99:247-57.

16. Godmann M, Lambrot R, Kimmins S. The dynamic epigenetic program in male germ cells: its role in spermatogenesis, testis cancer, and its response to the environment. Microsc Res Tech. 2009;72:603-19.

17. Goodman J, Counts J. Hypomethylation of DNA: a possible nongenotoxic mechanism underlying the role of cell proliferation in carcinogenesis. Environ Health Perspect. 1993;101 Suppl 5: $169-72$.

18. Esteller M. CpG island hypermethylation and tumor suppressor genes: a booming present, a brighter future. Oncogene. 2002;21: 5427-40.

19. Cheung T-H, Lo K, Yim S-F, Chan L, Heung M-S, Chan C-S, et al. Epigenetic and genetic alternation of PTEN in cervical neoplasm. Gynecol Oncol. 2004;93:621-7.

20. Michie A, McCaig A, Nakagawa R, Vukovic M. Death-associated protein kinase (DAPK) and signal transduction: regulation in cancer. FEBS J. 2010;277:74-80.

21. Yang N, Nijhuis E, Volders H, Eijsink J, Lendvai A, Zhang B, et al. Gene promoter methylation patterns throughout the process of cervical carcinogenesis. Cell Oncol: Off J Int Soc Cell Oncol. 2010;32:131-43.

22. Yang H, Liu V, Wang Y, Chan K, Tsang P, Khoo U, et al. Detection of hypermethylated genes in tumor and plasma of cervical cancer patients. Gynecol Oncol. 2004;93:435-40.

23. Ferreira H, Heyn H, Garcia Del Muro X, Vidal A, Larriba S, Muñoz C, et al. Epigenetic loss of the PIWI/piRNA machinery in human testicular tumorigenesis. Epigenetics: Off J DNA Methylation Soc. 2013;9:113-8. This paper is important because it shows the importance of hypermethylation-mediated silencing of small regulatory PIWI-interacting RNAs such as PIWIL1, PIWIL2, PIWIL4, which are involved in modulating testicular carcinogenesis.

24. Manton K, Douglas M, Netzel-Arnett S, Fitzpatrick D, Nicol D, Boyd A, et al. Hypermethylation of the $5^{\prime} \mathrm{CpG}$ island of the gene encoding the serine protease testisin promotes its loss in testicular tumorigenesis. Br J Cancer. 2005;92:760-9.

25. Kawamoto K, Enokida H, Gotanda T, Kubo H, Nishiyama K, Kawahara M, et al. p16INK4a and p14ARF methylation as a potential biomarker for human bladder cancer. Biochem Biophys Res Commun. 2006;339:790-6.
26. Lin $\mathrm{H}-\mathrm{H}, \mathrm{Ke} \mathrm{H}-\mathrm{L}, \mathrm{Wu}$ W-J, Lee Y-H, Chang L-L. Hypermethylation of E-cadherin, p16, p14, and RASSF1A genes in pathologically normal urothelium predict bladder recurrence of bladder cancer after transurethral resection. Urol Oncol. 2012;30: 177-81.

27. Clifford S, Prowse A, Affara N, Buys C, Maher E. Inactivation of the von Hippel-Lindau (VHL) tumour suppressor gene and allelic losses at chromosome arm $3 p$ in primary renal cell carcinoma: evidence for a VHL-independent pathway in clear cell renal tumourigenesis. Gene Chromosome Cancer. 1998;22:200-9.

28. Foster K, Crossey P, Cairns P, Hetherington J, Richards F, Jones $\mathrm{M}$, et al. Molecular genetic investigation of sporadic renal cell carcinoma: analysis of allele loss on chromosomes $3 \mathrm{p}, 5 \mathrm{q}, 11 \mathrm{p}$, 17 and 22. Br J Cancer. 1994;69:230-4.

29. Morrissey C, Martinez A, Zatyka M, Agathanggelou A, Honorio S, Astuti D, et al. Epigenetic inactivation of the RASSF1A 3p21.3 tumor suppressor gene in both clear cell and papillary renal cell carcinoma. Cancer Res. 2001;61:7277-81.

30. Costa V, Henrique R, Ribeiro F, Pinto M, Oliveira J, Lobo F, et al. Quantitative promoter methylation analysis of multiple cancerrelated genes in renal cell tumors. BMC Cancer. 2007;7:133.

31. Lv D, Zhao W, Dong D, Qian X-P, Zhang Y, Tian X-J, et al. Genetic and epigenetic control of UNC5C expression in human renal cell carcinoma. Eur J Cancer (Oxford, Engl: 1990). 2011;47: 2068-76.

32. Jerónimo C, Henrique R, Hoque M, Ribeiro F, Oliveira J, Fonseca $\mathrm{D}$, et al. Quantitative RARbeta2 hypermethylation: a promising prostate cancer marker. Clin Cancer Res: Off J Am Assoc Cancer Res. 2004;10:4010-4

33. Onay H, Pehlivan S, Koyuncuoglu M, Kirkali Z, Ozkinay F. Multigene methylation analysis of conventional renal cell carcinoma. Urol Int. 2009;83:107-12.

34. Morris M, Hesson L, Wagner K, Morgan N, Astuti D, Lees R, et al. Multigene methylation analysis of Wilms' tumour and adult renal cell carcinoma. Oncogene. 2003;22:6794-801.

35. Sasaki M, Tanaka Y, Perinchery G, Dharia A, Kotcherguina I, Fujimoto S, et al. Methylation and inactivation of estrogen, progesterone, and androgen receptors in prostate cancer. J Natl Cancer Inst. 2002;94:384-90.

36. Henrique R, Costa V, Cerveira N, Carvalho A, Hoque M, Ribeiro F, et al. Hypermethylation of cyclin D2 is associated with loss of mRNA expression and tumor development in prostate cancer. $\mathbf{J}$ Mol Med (Berl, Germany). 2006;84:911-8.

37. Yanatatsaneejit $\mathrm{P}$, Mutirangura A, Kitkumthorn N. Human papillomavirus's physical state and cyclin A1 promoter methylation in cervical cancer. Int J Gynecol Cancer: Off J Int Gynecol Cancer Soc. 2011;21:902-6.

38. Alumkal J, Zhang Z, Humphreys E, Bennett C, Mangold L, Carducci M, et al. Effect of DNA methylation on identification of aggressive prostate cancer. Urology. 2008;72:1234-9.

39. Carvalho J, Filipe L, Costa V, Ribeiro F, Martins A, Teixeira M, et al. Detailed analysis of expression and promoter methylation status of apoptosis-related genes in prostate cancer. Apoptosis: Int J Program Cell Death. 2010;15:956-65.

40. Lind G, Skotheim R, Lothe R. The epigenome of testicular germ cell tumors. APMIS. 2007;115:1147-60.

41. Kawakami T, Okamoto K, Sugihara H, Hattori T, Reeve A, Ogawa $\mathrm{O}$, et al. The roles of supernumerical X chromosomes and XIST expression in testicular germ cell tumors. J Urol. 2003;169:1546-52.

42. Lee W, Morton R, Epstein J, Brooks J, Campbell P, Bova $G$, et al. Cytidine methylation of regulatory sequences near the pi-class glutathione S-transferase gene accompanies human prostatic carcinogenesis. Proc Natl Acad Sci U S A. 1994;91:11733-7. 
43. Lodygin D, Epanchintsev A, Menssen A, Diebold J, Hermeking $\mathrm{H}$. Functional epigenomics identifies genes frequently silenced in prostate cancer. Cancer Res. 2005;65:4218-27.

44. Yegnasubramanian S, Kowalski J, Gonzalgo M, Zahurak M, Piantadosi S, Walsh P, et al. Hypermethylation of CpG islands in primary and metastatic human prostate cancer. Cancer Res. 2004;64:1975-86.

45. Maruyama R, Toyooka S, Toyooka K, Virmani A, Zöchbauer-Müller S, Farinas A, et al. Aberrant promoter methylation profile of prostate cancers and its relationship to clinicopathological features. Clin Cancer Res: Off J Am Assoc Cancer Res. 2002;8:514-9.

46. Jerónimo C, Henrique R, Hoque M, Mambo E, Ribeiro F, Varzim $\mathrm{G}$, et al. A quantitative promoter methylation profile of prostate cancer. Clin Cancer Res: Off J Am Assoc Cancer Res. 2004;10: 8472-8.

47. Yamada S, Kohu K, Ishii T, Ishidoya S, Ishidoya S, Hiramatsu M, et al. Gene expression profiling identifies a set of transcripts that are up-regulated inhuman testicular seminoma. DNA Res: Int J Rapid Publ Rep Genes Genomes. 2004;11:335-44.

48. Baldwin R, Nemeth E, Tran H, Shvartsman H, Cass I, Narod S, et al. BRCA1 promoter region hypermethylation in ovarian carcinoma: a population-based study. Cancer Res. 2000;60:5329-33.

49. Sathyanarayana U, Maruyama R, Padar A, Suzuki M, Bondaruk J, Sagalowsky A, et al. Molecular detection of noninvasive and invasive bladder tumor tissues and exfoliated cells by aberrant promoter methylation of laminin-5 encoding genes. Cancer Res. 2004;64:1425-30.

50. Li L, Zhao H, Nakajima K, Oh B, Ribeiro Filho L, Carroll P, et al. Methylation of the E-cadherin gene promoter correlates with progression of prostate cancer. J Urol. 2001;166:705-9.

51. Sathyanarayana U, Padar A, Suzuki M, Maruyama R, Shigematsu $\mathrm{H}$, Hsieh J-T, et al. Aberrant promoter methylation of laminin-5encoding genes in prostate cancers and its relationship to clinicopathological features. Clin Cancer Res: Off J Am Assoc Cancer Res. 2003;9:6395-400.

52. Yates D, Rehman I, Abbod M, Meuth M, Cross S, Linkens D, et al. Promoter hypermethylation identifies progression risk in bladder cancer. Clin Cancer Res: Off J Am Assoc Cancer Res. 2007;13:2046-53.

53. Horikawa Y, Sugano K, Shigyo M, Yamamoto H, Nakazono $\mathrm{M}$, Fujimoto $\mathrm{H}$, et al. Hypermethylation of an E-cadherin (CDH1) promoter region in high grade transitional cell carcinoma of the bladder comprising carcinoma in situ. J Urol. 2003;169:1541-5.

54. Lin Z, Gao M, Zhang X, Kim YS, Lee ES, Kim HK, et al. The hypermethylation and protein expression of $\mathrm{p} 16$ INK4A and DNA repair gene O6-methylguanine-DNA methyltransferase in various uterine cervical lesions. J Cancer Res Clin Oncol. 2005;131:364-70.

55. Bernstein BE, Meissner A, Lander ES. The mammalian epigenome. Cell. 2007;128:669-81.

56. Yuecheng Y, Hongmei L, Xiaoyan X. Clinical evaluation of Ecadherin expression and its regulation mechanism in epithelial ovarian cancer. Clin Exp Metastasis. 2006;23:65-74.

57. Lind G, Skotheim R, Fraga M, Abeler V, Esteller M, Lothe R. Novel epigenetically deregulated genes in testicular cancer include homeobox genes and SCGB3A1 (HIN-1). J Pathol. 2006;210: $441-9$.

58. Mirabello L, Savage SA, Korde L, Gadalla SM, Greene MH. LINE-1 methylation is inherited in familial testicular cancer kindreds. BMC Med Genet. 2010;11:77.

59. Gama-Sosa M, Slagel V, Trewyn R, Oxenhandler R, Kuo K, Gehrke C, et al. The 5-methylcytosine content of DNA from human tumors. Nucleic Acids Res. 1983;11:6883-94.
60. Weisenberger D, Campan M, Long T, Kim M, Woods C, Fiala E, et al. Analysis of repetitive element DNA methylation by MethyLight. Nucleic Acids Res. 2005;33:6823-36.

61. Ehrlich M, Woods C, Yu M, Dubeau L, Yang F, Campan M, et al. Quantitative analysis of associations between DNA hypermethylation, hypomethylation, and DNMT RNA levels in ovarian tumors. Oncogene. 2006;25:2636-45.

62. Qu G, Dubeau L, Narayan A, Yu M, Ehrlich M. Satellite DNA hypomethylation vs. overall genomic hypomethylation in ovarian epithelial tumors of different malignant potential. Mutat Res. 1999;423:91-101.

63.•• Rodriguez J, Vives L, Jordà M, Morales C, Muñoz M, Vendrell E, et al. Genome-wide tracking of unmethylated DNA Alu repeats in normal and cancer cells. Nucleic Acids Res. 2008;36:770-84. This paper investigates the commonly studied DNA hypomethylated repeats such as Alu repeats in normal and cancer cells. Global DNA hypomethylation is commonly observed in cancers therefore this is considered to be a very important contribution.

64. Kim M-J, White-Cross J, Shen L, Issa J-PJ, Rashid A. Hypomethylation of long interspersed nuclear element-1 in hepatocellular carcinomas. Mod Pathol: Off J U S Can Acad Pathol, Inc. 2009;22:442-9.

65. Florl A, Steinhoff C, Müller M, Seifert HH, Hader C, Engers R, et al. Coordinate hypermethylation at specific genes in prostate carcinoma precedes LINE-1 hypomethylation. Br J Cancer. 2004;91:985-94

66. Gaudet F, Hodgson J, Eden A, Jackson-Grusby L, Dausman J, Gray $\mathrm{J}$, et al. Induction of tumors in mice by genomic hypomethylation. Science (New York, NY). 2003;300:489-92.

67. Poirier L. Methyl group deficiency in hepatocarcinogenesis. Drug Metab Rev. 1994;26:185-99.

68. Ehrlich M. DNA methylation in cancer: too much, but also too little. Oncogene. 2002;21:5400-13.

69. Cadieux B, Ching T-T, VandenBerg S, Costello J. Genome-wide hypomethylation in human glioblastomas associated with specific copy number alteration, methylenetetrahydrofolate reductase allele status, and increased proliferation. Cancer Res. 2006;66: 8469-76.

70. Kaneda A, Tsukamoto T, Takamura-Enya T, Watanabe N, Kaminishi M, Sugimura T, et al. Frequent hypomethylation in multiple promoter $\mathrm{CpG}$ islands is associated with global hypomethylation, but not with frequent promoter hypermethylation. Cancer Sci. 2004;95:58-64.

71. Grunau C, Sanchez C, Ehrlich M, van der Bruggen P, Hindermann W, Rodriguez C, et al. Frequent DNA hypomethylation of human juxtacentromeric BAGE loci in cancer. Gene Chromosome Cancer. 2005;43:11-24.

72. Ogishima T, Shiina H, Breault J, Tabatabai L, Bassett W, Enokida $\mathrm{H}$, et al. Increased heparanase expression is caused by promoter hypomethylation and up-regulation of transcriptional factor early growth response-1 in human prostate cancer. Clin Cancer Res: Off J Am Assoc Cancer Res. 2005;11:1028-36.

73. Ateeq B, Unterberger A, Szyf M, Rabbani S. Pharmacological inhibition of DNA methylation induces proinvasive and prometastatic genes in vitro and in vivo. Neoplasia (New York, NY). 2008;10:266-78.

74. Chekhun V, Lukyanova N, Kovalchuk O, Tryndyak V, Pogribny I. Epigenetic profiling of multidrug-resistant human MCF-7 breast adenocarcinoma cells reveals novel hyper- and hypomethylated targets. Mol Cancer Ther. 2007;6:1089-98.

75. Yegnasubramanian S, Haffner M, Zhang Y, Gurel B, Cornish T, $\mathrm{Wu} \mathrm{Z}$, et al. DNA hypomethylation arises later in prostate cancer progression than $\mathrm{CpG}$ island hypermethylation and contributes to metastatic tumor heterogeneity. Cancer Res. 2008;68:8954-67. 
76. Wang Q, Williamson M, Bott S, Brookman-Amissah N, Freeman A, Nariculam J, et al. Hypomethylation of WNT5A, CRIP1 and S100P in prostate cancer. Oncogene. 2007;26:6560-5.

77. Pulukuri S, Estes N, Patel J, Rao J. Demethylation-linked activation of urokinase plasminogen activator is involved in progression of prostate cancer. Cancer Res. 2007;67:930-9.

78. Gama-Sosa M, Wang R, Kuo K, Gehrke C, Ehrlich M. The 5methylcytosine content of highly repeated sequences in human DNA. Nucleic Acids Res. 1983;11:3087-95.

79. Kim Y, Giuliano A, Hatch K, Schneider A, Nour M, Dallal G, et al. Global DNA hypomethylation increases progressively in cervical dysplasia and carcinoma. Cancer. 1994;74:893-9.

80. Widschwendter M, Jiang G, Woods C, Müller H, Fiegl H, Goebel $\mathrm{G}$, et al. DNA hypomethylation and ovarian cancer biology. Cancer Res. 2004;64:4472-80.

81. Patchsung M, Boonla C, Amnattrakul P, Dissayabutra T, Mutirangura A, Tosukhowong P. Long interspersed nuclear element-1 hypomethylation and oxidative stress: correlation and bladder cancer diagnostic potential. PLoS ONE. 2012;7.

82. Ogishima T, Shiina H, Breault J, Terashima M, Honda S, Enokida $\mathrm{H}$, et al. Promoter $\mathrm{CpG}$ hypomethylation and transcription factor EGR1 hyperactivate heparanase expression in bladder cancer. Oncogene. 2005;24:6765-72.

83. Ma L, Feugang J, Konarski P, Wang J, Lu J, Fu S, et al. Growth inhibitory effects of quercetin on bladder cancer cell. Front Biosci: J Virtual Libr. 2006;11:2275-85.

84. Lee W, Shim J-Y, Zhu B. Mechanisms for the inhibition of DNA methyltransferases by tea catechins and bioflavonoids. Mol Pharmacol. 2005;68:1018-30.

85. Berletch J, Liu C, Love W, Andrews L, Katiyar S, Tollefsbol T. Epigenetic and genetic mechanisms contribute to telomerase inhibition by EGCG. J Cell Biochem. 2008;103:509-19.

86. Lee A, Fraser M, Meng X, Binns C. Protective effects of green tea against prostate cancer. Expert Rev Anticancer Ther. 2006;6:507-13.

87. Johnson I, Belshaw N. Environment, diet and CpG island methylation: epigenetic signals in gastrointestinal neoplasia. Food Chem Toxicol: Int J Publ Br Ind Biol Res Assoc. 2008;46:134659.

88. Gao Z, Xu Z, Hung M-S, Lin Y-C, Wang T, Gong M, et al. Promoter demethylation of WIF-1 by epigallocatechin-3-gallate in lung cancer cells. Anticancer Res. 2009;29:2025-30.

89. Kato K, Long N, Makita H, Toida M, Yamashita T, Hatakeyama $\mathrm{D}$, et al. Effects of green tea polyphenol on methylation status of RECK gene and cancer cell invasion in oral squamous cell carcinoma cells. Br J Cancer. 2008;99:647-54.

90. Gu B, Ding Q, Xia G, Fang Z. EGCG inhibits growth and induces apoptosis in renal cell carcinoma through TFPI-2 overexpression. Oncol Rep. 2009;21:635-40.

91. Hirata H, Hinoda Y, Nakajima K, Kawamoto K, Kikuno N, Kawakami K, et al. Wnt antagonist gene DKK2 is epigenetically silenced and inhibits renal cancer progression through apoptotic and cell cycle pathways. Clin Cancer Res: Off J Am Assoc Cancer Res. 2009;15:5678-87.

92. Qi H, Ohh M. The von Hippel-Lindau tumor suppressor protein sensitizes renal cell carcinoma cells to tumor necrosis factorinduced cytotoxicity by suppressing the nuclear factor-kappaBdependent antiapoptotic pathway. Cancer Res. 2003;63:7076-80.
93. Fang M, Chen D, Sun Y, Jin Z, Christman J, Yang C. Reversal of hypermethylation and reactivation of p16INK4a, RARbeta, and MGMT genes by genistein and other isoflavones from soy. Clin Cancer Res: Off J Am Assoc Cancer Res. 2005;11:7033-41.

94. Li Y, Liu L, Andrews L, Tollefsbol T. Genistein depletes telomerase activity through cross-talk between genetic and epigenetic mechanisms. Int J Cancer J Int Cancer. 2009;125:286-96.

95. Day J, Bauer A, DesBordes C, Zhuang Y, Kim B-E, Newton L, et al. Genistein alters methylation patterns in mice. J Nutr. 2002;132:2419S-23S

96. Kikuno N, Shiina H, Urakami S, Kawamoto K, Hirata H, Tanaka $\mathrm{Y}$, et al. Genistein mediated histone acetylation and demethylation activates tumor suppressor genes in prostate cancer cells. Int $\mathrm{J}$ Cancer J Int Cancer. 2008;123:552-60.

97. Hirata H, Hinoda Y, Shahryari V, Deng G, Tanaka Y, Tabatabai Z, et al. Genistein downregulates onco-miR-1260b and upregulates sFRP1 and Smad4 via demethylation and histone modification in prostate cancer cells. Br J Cancer. 2014;110:1645-54. This paper is important because it discusses how the flavonoid Genistein modulates methylation of pro-tumorigenic miRNA-1260b and its targets SFRPI and Smad4, to inhibit prostate cancer cell proliferation and invasion. This shows that flavonoids have anti-cancer potential by modulating the methylation status of oncogenes.

98. Chen Y, Zaman M, Deng G, Majid S, Saini S, Liu J, et al. MicroRNAs 221/222 and genistein-mediated regulation of ARHI tumor suppressor gene in prostate cancer. Cancer Prev Res (Phila, Pa). 2011;4:76-86.

99. Rajnee Kanwal HS, Gupta S. Plant flavonoid apigenin preferentially binds with GC-rich DNA sequences and inhibits DNA methylation. Cancer Res. 2011;71:3683.

100. Fang M, Chen D, Yang C. Dietary polyphenols may affect DNA methylation. J Nutr. 2007;137:223S-8S.

101. Liu Z, Xie Z, Jones W, Pavlovicz R, Liu S, Yu J, et al. Curcumin is a potent DNA hypomethylation agent. Bioorg Med Chem Lett. 2009;19:706-9.

102. Parashar G, Parashar N, Capalash N. Curcumin causes promoter hypomethylation and increased expression of FANCF gene in SiHa cell line. Mol Cell Biochem. 2012;365:29-35.

103. Abusnina A, Keravis T, Yougbaré I, Bronner C, Lugnier C. Antiproliferative effect of curcumin on melanoma cells is mediated by PDE1A inhibition that regulates the epigenetic integrator UHRF1. Mol Nutr Food Res. 2011;55:1677-89.

104. Shu L, Khor T, Lee J-H, Boyanapalli SS, Huang Y, Wu T-Y, et al. Epigenetic $\mathrm{CpG}$ demethylation of the promoter and reactivation of the expression of Neurog1 by curcumin in prostate LNCaP cells. AAPS J. 2011;13:606-14.

105. Jha A, Nikbakht M, Parashar G, Shrivastava A, Capalash N, Kaur J. Reversal of hypermethylation and reactivation of the RAR $\beta 2$ gene by natural compounds in cervical cancer cell lines. Folia Biol. 2010;56:195-200.

106. Khor T, Huang Y, Wu T-Y, Shu L, Lee J, Kong A-NT. Pharmacodynamics of curcumin as DNA hypomethylation agent in restoring the expression of $\mathrm{Nrf} 2$ via promoter $\mathrm{CpGs}$ demethylation. Biochem Pharmacol. 2011;82:1073-8.

107. Wang Z, Li M, Lu S, Zhang Y, Wang H. Promoter hypermethylation of FANCF plays an important role in the occurrence of ovarian cancer through disrupting Fanconi anemia-BRCA pathway. Cancer Biol Ther. 2006;5:256-60. 